\title{
Transmission of Pneumocystis carinii from patients to hospital staff
}

Bettina Lundgren, Kerstin Elvin, Lotte P Rothman, Inger Ljungström, Christer Lidman, Jens D Lundgren

\begin{abstract}
Background - An extrahuman reservoir of human pathogenic Pneumocystis carinii remains unknown. Host to host transmission has been described in animal studies and in cluster cases among immunodeficient patients. $P$ carinii DNA has recently been detected in air filters from inpatient and outpatient rooms in departments of infectious diseases managing patients with $P$ carinii pneumonia (PCP), suggesting the airborne route of transmission. Exposure of staff to $P$ carinii may occur in hospital departments treating patients with PCP.
\end{abstract}

Methods - Exposure to $P$ carinii was detected by serological responses to human $P$ carinii by ELISA, Western blotting, and indirect immunofluorescence in 64 hospital staff with and 79 staff without exposure to patients with PCP from Denmark and Sweden. DNA amplification of oropharyngeal washings was performed on 20 Danish staff with and 20 staff without exposure to patients with PCP.

Results - There was no significant difference in the frequency or level of antibodies to $P$ carinii between staff exposed and those unexposed to patients with PCP. None of the hospital staff had detectable $P$ carinii DNA in oropharyngeal washings. Conclusions - There is no difference in antibodies and no detectable $P$ carinii DNA in oropharyngeal washings, which suggests that immunocompetent staff treating patients with PCP are not a potentially infectious source of $P$ carinii for immunocompromised patients.

(Thorax 1997;52:422-424)

Keywords: Pneumocystis carinii, transmission, serology, polymerase chain reaction.

Serological studies suggest that most children have been exposed to Pneumocystis carinii ${ }^{1-3}$ and it has previously been thought that $P$ carinii pneumonia in the immunocompromised host is a result of reactivation of a latent infection acquired asymptomatically in childhood. However, DNA amplification in necroscopic lung specimens from immunocompromised patients has failed to detect $P$ carinii $\mathrm{DNA},{ }^{4}$ nor has $P$ carinii been identified in immunosuppressed HIV infected patients without prior pulmonary disease. ${ }^{56}$ Animal studies with immunosuppressed rats have previously suggested an airborne route of infection. ${ }^{78}$ Host to host transmission has been described in rats and rhesus macaques, ${ }^{89}$ as well as in cluster cases among immunodeficient patients. ${ }^{10-13} P$ carinii DNA has recently been detected in air filters from animal facilities housing immunosuppressed rats with $P$ carinii pneumonia (PCP) as well as from air filters from inpatient and outpatient rooms in hospital departments treating patients with PCP. ${ }^{1415}$

Raised $P$ carinii antibody titres, detected by immunofluorescence, have previously been described in serum samples from staff in close contact with patients with PCP compared with staff without contact with AIDS patients. ${ }^{16}$ These results raise the question whether staff may transmit the microorganism from one patient to another, and whether the patient should be placed in respiratory isolation. In order to contribute to this debate we investigated the possible transmission of $P$ carinii from patients to staff by studying the serological responses and DNA amplification of oropharyngeal samples in hospital staff exposed and unexposed to patients with PCP.

\section{Methods}

Two groups of hospital staff exposed or unexposed to patients with PCP from Copenhagen, Denmark and Stockholm, Sweden were studied. The Danish group exposed to patients with PCP consisted of 38 doctors and nurses (17 women) of mean age 38 years who were handling patients with documented PCP at two infectious diseases departments in Copenhagen, each treating 20-40 patients with PCP per year. The Swedish group consisted of 26 nurses ( 21 women) of mean age 37 years working at one infectious diseases department in Stockholm where about 20 patients with PCP were diagnosed and treated yearly. The staff had worked at the infectious diseases departments for at least six months and were in close contact with patients with PCP during diagnostic bronchoscopy and in the daily handling and care of the patients. The Danish staff unexposed to patients with PCP were 40 staff members (29 women) of mean age 37 years from a blood bank and a surgery gastroenterological department at a hospital without an infectious diseases department. The corresponding Swedish group were 39 staff members ( 27 women) of mean age 35 years from a surgery department at the same hospital as the exposed staff. The unexposed staff had not previous been employed in an infectious diseases department. All 143 subjects were healthy and received no immunosuppressive drugs. Specimens of serum were drawn from all subjects and stored at $-20^{\circ} \mathrm{C}$ for antibody testing. Oropharyngeal washings were obtained from 


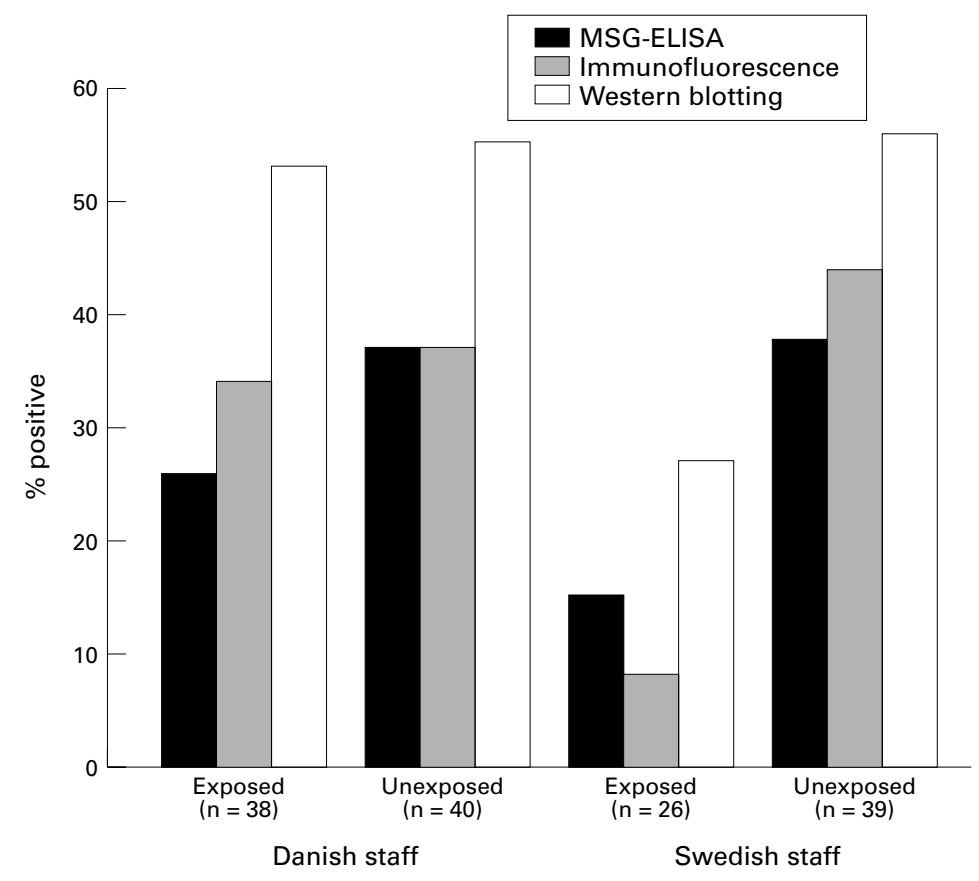

Figure 1 Percentage of subjects with antibodies to P carinii detectable by MSG-ELISA, immunofluorescence, and Western blotting among hospital staff exposed and unexposed to patients with P carinii pneumonia in Denmark and Sweden. No significant differences were found between the Danish groups of staff.

20 subjects in the exposed and unexposed group from Denmark by rinsing and gargling their mouths with $10 \mathrm{ml}$ sterile saline within two days of diagnosing a patient with PCP. All specimens were randomised and coded to ensure blind testing.

\section{DETECTION OF ANTIBODIES}

Antibody responses to human $P$ carinii antigens of $95 \mathrm{kD}$ (the major surface antigen, MSG), $60 \mathrm{kD}$, and $40 \mathrm{kD}$ were detected by Western blotting using serum diluted $1 / 100 .{ }^{17}$ Indirect immunofluorescence was performed using paraffin sections of human lung infected with $P$ carinii as antigen and serum specimens diluted $1 / 10$ as previously described. ${ }^{18}$ Specimens resulting in fluorescing $P$ carinii were positive. The titre of the specimen was the highest dilution of serum giving a positive result. Using a previously described MSG-ELISA ${ }^{19-21}$ IgG antibodies to MSG of $P$ carinii were detected using serum diluted $1 / 100$. A positive sample had an optical density of $>0.20$.

\section{DNA AMPLIFICATION}

DNA was extracted from $2 \mathrm{ml}$ of oropharyngeal washings using proteinase $\mathrm{K}$ digestion followed by phenol chloroform extraction. The poly-

Table 1 Levels of antibodies to Pneumocystis carinii detected by MSG-ELISA (OD) and immunofluorescence (titre) in staff members with detectable antibodies exposed and unexposed to P carinii pneumonia

\begin{tabular}{llllll}
\hline & \multicolumn{4}{l}{ Median antibody levels (number of patients) } \\
\cline { 2 - 3 } \cline { 5 - 6 } \cline { 5 - 6 } & Exposed staff & & \multicolumn{2}{l}{ Unexposed staff } \\
\cline { 2 - 3 } \cline { 5 - 6 } & Danish & Swedish & & Danish & Swedish \\
\hline MSG-ELISA (OD) & $0.49(10)$ & $0.33(4)$ & & $0.35(15)$ & $0.32(15)$ \\
Immunofluorescence (titre) & $10(13)$ & $30(2)$ & & $20(15)$ & $20(17)$ \\
\hline
\end{tabular}

No significant differences were found between the groups of staff $(p>0.1)$. merase chain reaction using $P$ carinii specific mitochondrial ribosomal RNA primers was carried out as previously described. ${ }^{22}$ Appropriate positive and negative controls were run in each experiment.

DATA ANALYSIS

The Mann-Whitney test was used to test for differences in levels of antibodies and the $\chi^{2}$ test for differences in frequency of antibodies between groups.

\section{Results}

The percentage of serum specimens with antibodies to $P$ carinii detected by three different immunological techniques (ELISA, immunofluorescence, and Western blotting) in Danish and Swedish staff exposed and unexposed to patients with PCP is shown in fig 1. There were no significant differences in the frequency of antibodies to MSG or human $P$ carinii between Danish exposed staff and Danish and Swedish unexposed staff members $(p>0.1)$. When the Swedish exposed staff members were compared with the Swedish unexposed staff members significantly fewer had detectable antibodies against MSG ( $\mathrm{p}<0.05)$ and against $P$ carinii by immunofluorescence $(\mathrm{p}<0.05)$, but not by Western blotting $(\mathrm{p}>0.1)$.

In those with detectable antibodies, no significant differences were found in the level of antibodies detected by MSG-ELISA and immunofluorescence among the four groups of staff studied (table 1).

Of the total 143 serum samples, all three tests were positive in $27(19 \%)$ and negative in 66 $(46 \%)$ samples. Of the remaining samples, 32 had concordance between two of the tests (all positive by Western blotting, 17 MSG-ELISA, and 15 immunofluorescence). In 18 samples only one test was positive (13 Western blotting and five immunofluorescence). Thus, all MSGELISA positive serum samples were confirmed by the $95 \mathrm{kD}$ band in Western blots whereas the $40 \mathrm{kD}$ and/or the $60 \mathrm{kD}$ bands confirmed 38 of 47 immunofluorescence positive samples. Only four of the immunofluorescence positive samples were confirmed exclusively by the $95 \mathrm{kD}$ band.

Oropharyngeal washings obtained from 20 Danish exposed staff members and 20 samples from Danish unexposed staff members were examined by a previously described polymerase chain reaction technique using $P$ carinii specific mitochondrial ribosomal RNA primers. ${ }^{22}$ In none of the 40 oropharyngeal washings were $P$ carinii specific amplification products seen.

\section{Discussion}

Leigh et al have previously reported increased titres of $P$ carinii antibodies using immunofluorescence in 24 hospital staff (mean age 24 years) in close contact with patients with PCP compared with 24 staff at a nursing home (mean age 42 years) and found an overall prevalence of antibodies in the 48 staff members of $96 \%{ }^{16}$ These results contrast with our 
findings where only $36 \%$ of the 78 Danish hospital staff and $29 \%$ of the 65 Swedish hospital staff had antibodies to $P$ carinii detected by immunofluorescence. Despite using three different methods, we were unable to show either a significantly higher frequency or level of antibodies to $P$ carinii in exposed than in unexposed staff members. Variation of seroprevalence in the background population, in populations of different age groups, and possible differences in the numbers of subjects studied may explain the discrepancies between the studies. One explanation for the fact that staff members exposed to patients with PCP did not develop an increased antibody titre to $P$ carinii is that the immunocompetent subjects eliminate the $P$ carinii organisms without mounting a measurable antibody response. Alternatively, the staff member may not have had a high enough exposure (number of $P$ carinii organisms) to mount the antibody response.

Different prevalences of antibodies to P carinii, varying from $3 \%$ to $90 \%$ in the adult population, have been reported. ${ }^{2182324}$ The differences may be explained by geographical regional variation and the use of different immunological methods and antigens. ${ }^{21823-26}$ The frequency of antibodies to MSG determined by ELISA found in our study correlates with previous results where $33 \%$ of healthy controls had antibodies. ${ }^{19}$ A variation was also found in our study population. The most likely explanation for this is the relatively small number of subjects tested in the group in which the lowest frequency of antibodies was detected - that is, the Swedish exposed staff members. In general there was good agreement between the three immunological tests used. The results of immunofluorescence and MSG-ELISA were complementary, MSG-ELISA detecting only the $95 \mathrm{kD}$ band whereas immunofluorescence reacts preferably with the $40 \mathrm{kD}$ and $60 \mathrm{kD}$ bands.

It has previously been shown that $P$ carinii specific amplification products can be detected in oropharyngeal washings from HIV infected patients with verified PCP by the polymerase chain reaction with a sensitivity of $72 \%$ compared with the corresponding results in bronchoalveolar lavage fluid. ${ }^{22}$ Furthermore, $P$ carinii specific DNA has been detected in air filters in hospital rooms housing patients with PCP. ${ }^{14} \mathrm{We}$ therefore investigated oropharyngeal washings from 20 Danish staff members exposed to patients with PCP and 20 unexposed staff members. $P$ carinii DNA was not detected in any of the 40 specimens. It is possible that $P$ carinii is not transmitted to the pharynges in levels detectable by the polymerase chain reaction. However, it is also possible that the oropharyngeal washings were not obtained soon enough after exposure to the patients with PCP, and rapid elimination of the organism may explain the negative results of the polymerase chain reaction.

In conclusion, we have been unable to show that $P$ carinii is transmitted from patient to staff to such an extent that it results in increased antibody responses to the microorganism or sufficient $P$ carinii specific DNA to be detected by polymerase chain reaction in oropharyngeal washings. Our results therefore suggest that immunocompetent individuals are probably unable to spread the organism to immunodeficient patients.

This study was sponsored in parts by ECA BIOMED-1, "PneuFoundation. The authors thank Aase Mayer and Lena Lundin for technical assistance.

1 Mauwissen JHET, Tauber I, Leewemberg ADEM, Beckers PJA, Sieben M. Parasitologic and serologic observations of infection with pneumocystis in humans. F Infect Dis 1977;136:43-9.

2 Lundgren B, Lebech M, Lind C, Nielsen JO, Lundgren JD. Antibody responses to a human Pneumocystis carinii surface
antigen in immunocompetent patients and in patients with atypical pneumonia. Eur f Clin Microbiol Infect Dis 1993; atypical pneur $105-9$.

3 Pifer LL, Hughes WT, Stagno S, Woods D. Pneumocystis carinii infection: evidence for high prevalence in normal and immunosuppresed children. Pediatrics 1978;61:35-41

4 Peters SE, Wakefield AE, Sinclair K, Millard PR, Hopkin JM. A search for Pneumocystis carinii in post-mortem lungs by DNA amplification. $\mathcal{F}$ Pathol 1992;166:195-8.

5 Ognibene FP, Masur H, Rogers P, Travis WD, Suffredini $\mathrm{AF}$, Feuerstein I, et al. Nonspecific interstitial pneumonitis without evidence of Pneumocystis carinii in asymptomatic patients infected with human immunodeficiency virus (HIV). Ann Intern Med 1988;109:874-9.

6 Lundgren JD, Orholm M, Nielsen TL, Iversen J, Hertz $J$, Nielsen JO. Bronchoscopy of symptom free patients infected with human immunodeficiency virus for detection of pneumocystosis. Thorax 1989;44:68-9.

7 Hughes WT. Natural mode of acquisition for de novo infection with Pneumocystis carinii. F Infect Dis 1982;145:842-8.

8 Sukura A, Lidberg L, Soveri T, Guerrero O, Chinchilla M, Elvin K, et al. Establisment of Pneumocystis carinii infection Elvin K, et al. Establisment of Pneumocystis carinii in

9 Vogel P, Miller CJ, Lowenstine LL, Lackner AA. Evidence for horizontal transmission of pneumonia on simian imfor horizontal transmission of pneumonia on simian imDis 1993;168:836-43.

10 Barzinsky JH, Phillips JE. Pneumocystis pneumonia transmission between patients with lymphoma. FAMA 1969 209:1527.

11 Goesch TR, Göts G, Stellbrinck KH, Albrecht H, Weh HJ, Hossenfeld DK. Possible transfer of Pneumocystis carini between immunodeficient patients. Lancet 1990;336:627

12 Bensousan T, Garo B, Islam S, Bourbigout B, Cledes J, Garre M. Possible transfer of Pneumocystis carinii between kidney transplant recipients. Lancet 1990;336:1066-7.

13 Chave J-P, David S, Wauters J-P, Van Melle G, Francioli P. Transmission of Pneumocystis carinii from AIDS patients to other immunosuppressed patients: a cluster of Pneumocystis carinii pneumonia in renal recipients. AIDS 1991; 5:927-32

14 Bartlett M, Lee C-H, Lu J-J, Bauer NL, Bettz JF, McLaughlin GL, et al. Pneumocystis carinii detected in air. $F$ Eukaryot Microbiol 1994;41:75S.

15 Olsson M, Sukura A, Lindberg L-A, Linder E. Detection of Pneumocystis carinii DNA by filtration of air. Scand $\mathcal{F}$ Infect Dis 1996;28:279-82.

16 Leigh TR, Millett MJ, Jameson B, Collins JV. Serum titres of Pneumocystis carinii antibody in health care workers caring for patients with AIDS. Thorax 1993;48:619-21.

17 Kovacs JA, Halpern JL, Lundgren B, Swan JC, Parillo JE Masur H. Monoclonal antibodies to Pneumocystis carinii: identification of specific antigens and characterization of antigenic differences between rat and human isolates. $f$ antigenic differences between
Infect Dis 1989;159:60-70.

18 Elvin K, Björkman A, Heurlin N, Ericsson BM, Barkholt L, Linder E. Seroreactivity to Pneumocystis carinii in patients with AIDS versus other immunosuppressed patients. Scand F Infect Dis 1994;26:33-40.

19 Lundgren B, Lundgren JD, Nielsen T, Mathiesen L, Nielsen JO, Kovacs JA. Antibody responses to a major Pneumocystis carinii antigen in human immunodeficiency virus-infected patients with and without $P$. carinii pneumonia. $\mathcal{F}$ Infect Dis 1992;165:1151-5.

20 Harries AD. The association between HIV and tuberculosis in the developing world. In: Davies PDO, ed. Clinical tuberculosis. London: Chapman and Hall, 1994: 241-64.

21 Franceshi S, Maso DL, La Vecchia C, Negri E, Serraino D. AIDS incidence rates in Europe and in the United States. AIDS 1994;8:1173-7.

22 Wakefield AE, Miller RF, Guiver LA, Hopkin JM. Oropharyngeal samples for detection of Pneumocystis carinii by DNA amplification. $Q \mathcal{F}$ Med 1993;86:401-6.

23 Kovacs JA, Halpern JL, Swan JC, Moss J, Parillo JE, Masur H. Identification of antigens and antibodies specific for Pneumocystis carinii. F Immunol 1988;140:2023-31.

24 Peglow SL, Smulian SL, Linke MJ. Serologic responses to Pneumocystis carinii antigens in health and disease. F Infect
Dito Pis 1990;161:296-306.

25 Lundgren JD, Barton SE, Lazzarin A, Danner S, Goebel FD, Pehrson P, et al. Factors associated with the occurrence of Pehrson P, et al. Factors associated with the occurrence of
Pneumocystis carinii pneumonia in 5025 European AIDS Pneumocystis carinii pneumonia in 5025 European AIDS
patients. AIDS in Europe Study Group. Clin Infect Dis patients. AIDS in

26 Lundgren B, Lipschik GY, Kovacs JA. Purification and characterization of a major human Pneumocystis carini surface antigen. $\mathcal{f}$ Clin Invest 1991;87:163-70. 